\title{
Using a GIS-Based Network Analysis and Optimisation Routines to Evaluate Service Provision: A Case Study of the UK Post Office
}

\author{
Alexis Comber • Chris Brunsdon • Jefferson Hardy • \\ Rob Radburn
}

Received: 3 September 2008 / Accepted: 14 November 2008 /

Published online: 5 December 2008

(C) Springer Science + Business Media B.V. 2008

\begin{abstract}
Many post offices in the UK have been or are in the process of being closed. The process of deciding which post office to close has been criticised for a lack of transparency and evidence. This work analysed the impact of proposed post office closures in an English county against national access criteria. Only one of five access criteria were satisfied by current proposals. An optimisation model was then used to identify alternative sets of post offices to close by minimising the 'losers' in terms of increased access distance for a) the whole population b) limiting long-term illness, and c) full time carers. Combining a GIS-based network analysis with an optimisation model was shown be an appropriate method to minimise the numbers of targeted groups who experience a decline in post office accessibility. As national targets will result locally in 'winners and 'losers', the method is a tool for generating evidence in support of policy, it allows sub-national analyses (e.g. at a local authority level) of the impacts of closures and can identify alternative closures better suited to local priorities.
\end{abstract}

Keywords Spatial planning $\cdot$ Network analysis $\cdot$ Optimisation $\cdot$ Accessibility $\cdot$ Retail

\section{Introduction}

In the UK post offices provide a valuable multifaceted resource for many different sectors of the community. Their importance was reflected a recent local study into rural sustainability which weighted the importance of post offices higher than other facilities as they were seen to provide 'services that are more essential to daily life'

\footnotetext{
A. Comber $(\bowtie) \cdot$ C. Brunsdon

Department of Geography, University of Leicester, Leicester LE1 7RH, UK e-mail: ajc36@le.ac.uk

J. Hardy $\cdot$ R. Radburn

Leicestershire County Council, County Hall, Glenfield, Leicester LE3 8RA, UK
} 
(Boston Borough Council 2006). Similarly, Age Concern (2006) note that they provide a lifeline for older people, carrying information about local events and facilities as well as providing local banking and shopping facilities. For many elderly people the post office is a 'one-stop shop' allowing them to access their pensions and benefits, to pay bills, and to meet and socialise with others. Rural post offices have been decline and the Commission for Rural Communities (2007) noted that a lack of availability of a number of key services including post offices can lead to 'service deserts'.

The history of UK post offices provides some context to the current situation. Until the 1969 Post Office Act, the Post Office was department of central government. The 1969 Act established the Post Office as a public corporation and in 1981 responsibility for postal services was separated from telecommunications. Currently the UK network of post office branches are operated and managed by nationally Post Office Limited as retail businesses and locally by a sub-postmaster (the position of the sub-postmaster is that of independent business owner). Post Office Limited is a wholly owned subsidiary of as part of Royal Mail Group plc. Postal services in the UK are regulated by the independent regulator, Postcomm (the Postal Services Commission) which was set up under the Postal Services Act 2000 as a non-ministerial government department. One of the tools used by Postcomm to regulate postal services (including Royal Mail) is the Universal Service Obligation. This ensures a standard fee for the delivery of letters and parcels, guarantees daily deliveries and is distinctive amongst retail business. Since 2000, private companies have been able to compete with Royal Mail in the bulk mail market (around 30\% of the UK letter market by value). The Government also provides a subsidy to Post Office Ltd to maintain the national network of post offices (the Social Network Payment), which has provided $150 \mathrm{~m}$ per year for rural and urban post offices. This subsidy was withdrawn in 2008. Some alternative delivery models have been developed such as mobile Post Offices but the rural Post Office network faces particular difficulties due to changes in customer use-only 1,500 of the 8,000 rural post offices are making money for Post Office Ltd (Postcomm 2006). The regulator opened up the market fully in 2006.

In May 2007 the government announced the Network Change closure programme 2007-2009, a plan to close 2,500 post offices (Post Office Ltd 2008). The closure programme will be completed by the end of 2008 and 11,700 post offices will remain compared to the 1960 's when there were $\sim 25,000$ post offices. The immediate reasons for the closures are because fewer people use post offices as traditional services (e.g. social security benefit payments) are now available online or directly via banks. Some groups have traced the origins of the post office closures to EU directive $97 / 67 / \mathrm{EC}$ which specified that the delivery of postal items of more than $100 \mathrm{~g}$ be opened up to competition (European Community 1997). The result of this legislation in the UK was competition in the traditional Post Office market from DHL, TNT as well as the state subsidised German Post Office amongst others. One of the financial consequences of the open market was that by 2006 Postcomm, the Post Office regulator, estimated that 6,500 rural post offices were running at a financial loss. According to Postwatch (an independent postal service pressure group) the post office network lost more than $£ 200$ million in $2006 / 7$ alone and the 2006-2008 period saw four million fewer customer visits every week. The impacts 
of this decline in Post Office usage has been felt most in rural areas and urban areas of deprivation (Postwatch 2008).

As part of the Network Change programme minimum distance 'access criteria' were put in place by the government to protect consumers in rural and remote areas and in deprived urban areas (Post Office Ltd 2008):

Criterion 1: $99 \%$ of the UK population to be within 3 miles and $90 \%$ of the population to be within 1 mile of a post office;

Criterion 2: $99 \%$ of the total population in deprived urban areas across the UK to be within 1 mile of their nearest post office;

Criterion 3: $95 \%$ of the total urban population across the UK to be within 1 mile of their nearest post office;

Criterion 4: $95 \%$ of the total rural population across the UK to be within 3 miles of their nearest post office; and

Criterion 5: For each individual postcode district, 95\% of the population of the postcode district to be within 6 miles of their nearest post office.

The motivation for this paper is to demonstrate how a GIS network analyses of access to post offices in conjunction with statistical analysis of demographic data can be used to evaluate the impacts of closures for businesses and retail outlets such as post office on different groups. The analysis can be used to provide the input into routines that optimise proposed closures according to the specified criteria. Specifically the aim of this work was to:

1) Evaluate the access criteria in an English county. Local authorities have the ability and opportunity to take remedial measures to counter the social and economic impacts of post office closures. For these reasons, studies evaluating access criteria at a local level are critical to local decision making and resource allocation.

2) Evaluate the 'fairness' of proposed closures by quantifying the extent to which different sectors of the community are adversely affected by the spatial distribution of post office closures. Recent work by Comber et al. (2008) has developed a method for quantifying relative access to different community goods and services for different community groups.

3) Develop a method for optimising the impacts of post office closures and thereby to provide evidence in support of spatial planning and policy.

\section{Background}

\section{GIS and Access}

There is a wealth of literature describing GIS-based studies of accessibility to different features, for instance greenspace, transport and health. These analyses quantify access in terms of distances or travel times and typically evaluate accessibility against some criteria. Examples of this type of analysis are described in a number of papers from the GIS literature and other disciplinary journals. Comber et al. (2008) quantified the provision of greenspace access amongst different 
ethnic and religious groups using a network analysis of access combined with a logistic regression of census data attributes. This method is generic and can be used to quantify the relative access to any spatial feature for different socio-economic groups. Onega et al. (2008) analysed access to specialised cancer care for different socio-economic and ethnic groups in the USA. Wyatt (1997) used a network analysis to analyse the influence of accessibility on property values. Schuurman et al. (2006) identified the spatial catchments of hospital healthcare services for those living in rural areas of British Columbia. Devlin et al. (2008) compared different routing strategies for the timber industry in Ireland. The interested reader is directed to reviews of the GIS and accessibility literature in O'Sullivan et al. (2000) for transport accessibility and McLafferty (2003) for access to health.

There has been little work describing the use of GIS to analyse access to post offices. White et al. (1997) applied a GIS approach to analyse changes in post office provision in South Wales and the subsequent impacts on accessibility. They noted that post offices are one of the key services in rural communities (along with education, health facilities and public transport) and that the least mobile groups in rural areas make the most use of post offices. Their analysis of post office closures suggested that decreased post office provision was weakly correlated to sociodemographic indicators and that post office closures in the period 1979-1994 did not affect disadvantaged groups more severely. One of the key recommendations of their work was that spatial analyses be incorporated into indicators of the viability and vitality of rural communities.

The papers by White et al. (1997) and Higgs and White (1997) are also representative of an emerging literature exploring the use of GIS to analyse access to services in relation to rural sustainability. However the use of spatial analytical tools is yet to permeate into national policy reporting of access and equity. The Commission on Rural Communities reports each year on 'the State of the Countryside' by collating quantitative information on social, economic and environmental issues in rural areas. Despite specific focus on 'equity' as one its themes, the State of the Countryside 2007 report (Commission on Rural Communities 2007) provide only simple area summaries of access to different community goods and services. No use is made of advanced spatial analyses to identify and quantifying local patterns of access. For instance, the report describes the percentage of households within $2 \mathrm{~km}$ of a post office for each of the eight rural and urban classes (Bibby and Shepherd 2004) but does not analyse the access to post offices in terms of different specific demographic and socio-economic groups.

\section{National Criteria for Access to Post Offices}

The national criteria for access to post offices (as detailed in Section 1) are themselves not without controversy. The House of Commons Business and Enterprise Committee, reporting on the proposed post office closures in May 2008 noted concerns about the plans for closures and the criteria by which closures would be determined:

'Several local authorities had given us evidence suggesting that Post Office Ltd had not taken adequate account of the information they had provided about 
local conditions and plans' (House of Commons Business and Enterprise Committee 2008 P5).

The committee commented further on the need for analysis at a local level into the impact of post office closures:

'There is a local criterion contained within the minimum access criteria, namely that $90 \%$ of the population in each Postcode District must be within 6 miles of their nearest Post Office outlet',

and

'that the "no one area to be overall significantly more adversely affected than any other area" requirement provides further local protection' (House of Commons Business and Enterprise Committee 2008 P31).

The post office regulator, ${ }^{1}$ Postcomm, has been quite scathing about the UK government's strategy for the post office network, noting that the national access criteria are confusing as currently set out (Postcomm 2007). In its response to the UK government's consultation document Postcomm stated:

'The [consultation] document does not explain how the access criteria were calculated or how the number of closures $(2,500)$ was arrived at. It is not clear if this proposed proposal will bring about a long term solution, or act as an interim measure, trying to balance the reasonable needs of users, the subpostmasters' need to make a viable living, and Post Office Ltd's desire to stop running at a loss. Has work been conducted to assess the exact impact of these changes and how long it will be before they need to be re-assessed?' (Postcomm 2007 P2).

Postcomm were also concerned that no analysis of national access criteria was planned:

'How will the national access criteria be enforced, and who will check that it meets the terms set out, including taking into account local conditions such as rivers, mountains, valleys, motorways and sea crossings to islands? How will access actually be calculated? What tools will be used to calculate it and what measures will be put in place to ensure they continue to be met?' (Postcomm 2007 P5).

\section{Summary}

There is a need for spatially detailed analysis of the impacts of post office closures in relation to the national access criteria. The guidelines for closures are contentious and have not been evaluated. Local analyses of the impacts of closures have been recommended specifically in relation to different socio-economic and demographic

\footnotetext{
${ }^{1}$ In the UK the regulator acts as a buffer between the government minister and the activities of the ministry: the minister is 'accountable' but the regulator is 'responsible' (Ed Balls, BBC Today programme, 18th July 2008).
} 
groups. GIS technologies offer spatial analytical techniques to compare access to post offices before and closures and to link to demographic information such as census data.

\section{Methods}

\section{Study Area and Data}

The study was conducted in Leicestershire, a county in the English Midlands, and the city of Leicester with a combined population of $\sim 900,000$ at the last census in 2001. Of the 181 post offices in Leicester and Leicestershire, 149 are to be retained, 24 are to be closed and 8 are become 'outreach' post offices ${ }^{2}$

The data assembled to study access included:

i) A road dataset for Leicester and Leicestershire with a $3 \mathrm{~km}$ external buffer, the OS MasterMap ITN layer which was cleaned to get rid of "Private Road Restricted Access" data objects; ${ }^{3}$

ii) Lower Super Output Area (LSOA) population weighted centroids point dataset;

iii) Point layer of post offices in Leicester and Leicestershire and the immediate surrounding areas, with attributes indicating planned closure, Eastings and Northings.

The LSOA polygons were provided by the Office of National Statistics and nationally have a minimum population of 1000 people (a mean of 1500). Lower Super Output Areas are constructed from groups of Output Areas (typically 4-6) and constrained by the boundaries of wards used for 2001 Census outputs. A description of Output Areas can be found at http://www.statistics.gov.uk/geography/census geog.asp. The 34,378 Lower Layer SOAs in England and Wales were generated by a computer programme which merged OAs taking into account measures of population size, mutual proximity and social homogeneity. The LSOA attributes were downloaded from $\mathrm{Casweb}^{4}$ (census data), the Office of National Statistics (Urban and Rural classification-Bibby and Shepherd 2004), UKBorders/Edina (post code districts) and the Department for Communities and Local Government (indices of multiple deprivation). The planned post office closures data was provided by Leicestershire County Council but full details if post office closures are publicly available.

\section{Network Analysis of Access}

A network analysis was applied to calculate distances between each Post Office 'Supply' to each LSOA population weighted centroid 'Demand'. The post office

\footnotetext{
${ }^{2}$ Outreach post offices include mobile post offices, services with a local partner such as a pub landlord, hosted services where a post office is set up for restricted hours on the premises of another business and home delivery of services ordered over the phone.

3 C C Crown Copyright/database right 2008. An Ordnance Survey/EDINA supplied service

${ }^{4} \mathrm{http}: / /$ www.census.ac.uk/casweb/
} 
locations were generated from their postcodes and the expectation is that they are on a road. Many of the LSOA population weighted centroids points do not sit directly on the road network. This analysis has assumed that the underestimated distances for some of the population will be balanced by the overestimated distances for others within each LSOA. Figure 1 shows a typical example.

A distance matrix was generated between each of the 181 post offices and the 583 LSOA points. This 'access' table was linked into 2001 census attributes on Age (census classes KS02 Age structure) and Health (KS08 Health and provision of unpaid care), to urban and rural classifications and to indices of deprivation.

It was noted that after the proposed closures, 133 post offices were closest to at least one of the LSOAs. This analysis sought to determine whether an alternative subset of 133 post offices could be identified using optimisation techniques to provide more equitable overall access. The choices were made on the basis of all 181 post offices, regardless of whether they have been nominated for closure, retention or outreach under current policy. The aim was to explore alternatives to this policy.

The method of exploration uses a grouping genetic algorithm (GGA) (Falkenauer 1999) to find a subset of 133 from 181 post offices that maximises an objective function. This was achieved by modifying the 'genalg' package contributed the R statistical programming language project (R Development Core Team 2008) by Egon Willighagen. This library provides a series of genetic algorithm tools, which the authors have augmented to provide a 'best subset selection' grouping genetic algorithm, given an objective function to optimise. The code may be supplied on

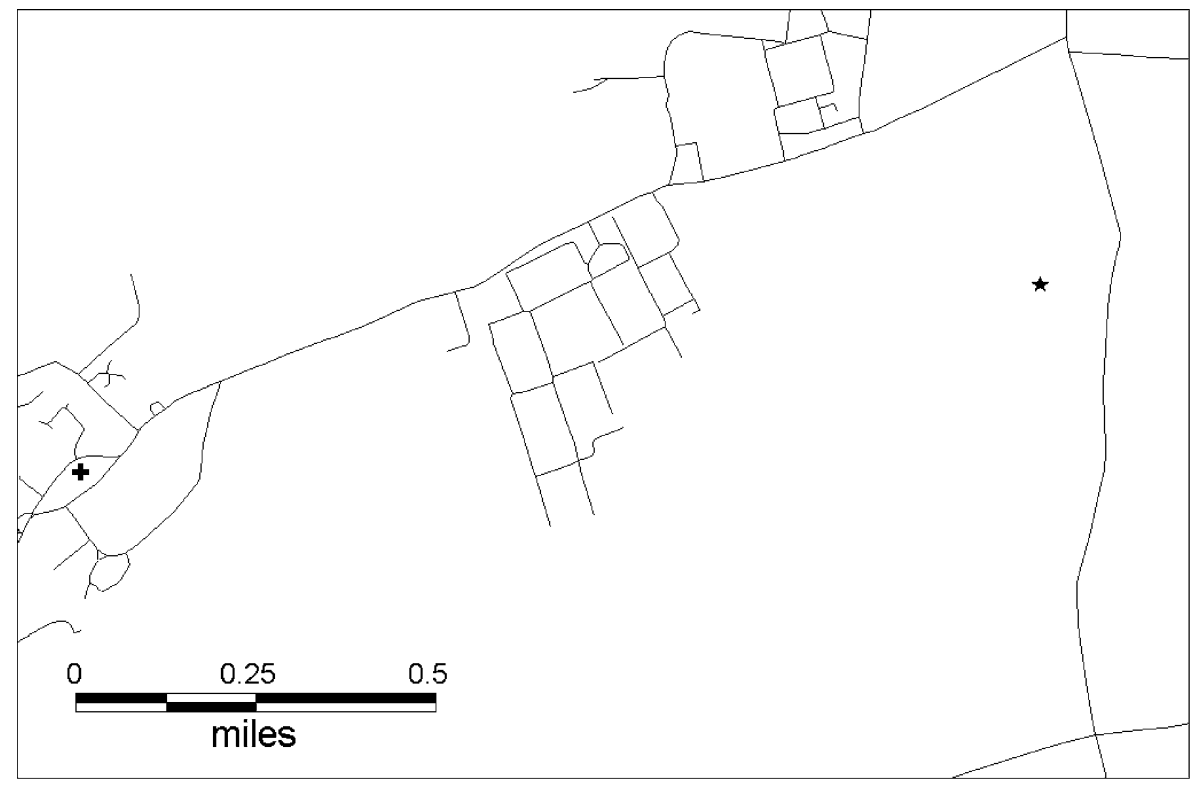

Fig. 1 An example of network distance underestimation between an LSOA centroid (star) and a post office (cross) 
request. Here, three different objective functions were investigated. In each case they take the form

$$
\frac{\sum_{i=L S O A} p_{i} d_{i j}}{\sum_{i=L S O A} p_{i}}
$$

where $i$ indexes the LSOAs in Leicester and Leicestershire, $p_{i}$ is the population of LSOA $i$ and $d_{i j}$ is the distance between LSOA $i$ and post office $j$, with $j$ being the index of the nearest post office to LSOA $i$ under a given choice of 133 post offices. This objective function may be interpreted as the population weighted average distance to the nearest post office.

For the three different functions, the only difference is which population, $p_{i}$ represents. In the first case it is the total population of each LSOA. In the second case it is the population with limiting long term illness (LLTI) and in the third, it is the population of unpaid carers with care duties exceeding $50 \mathrm{~h}$ per week. Thus the objective functions measure accessibility for the entire population, or subsets of the population falling into particular categories - the categories used here were chosen to be ones typifying sections of the population having special needs. The GGA attempts to find the subset of 133 post offices that minimises the value of the objective function.

\section{Results}

Initial Exploration

An initial exploration of the data showed the changes in the spatial distribution of the travel distance zones (1 mile, 3 miles, 6 miles) to post offices in Leicester and Leicestershire before and after the proposed closures (Fig. 2). Table 1 shows the numbers of LSOA centroids in different zones before and after the proposed post office closures. The major shift is in the number moving from the 'less than 1 mile' zone to the '1-3 mile' zone (74 out of 488) (see Table 1) after the proposed closures.

\section{Network Change Access Criteria}

Minimum distance criteria were specified as part of the Network Change programme. Each of these was evaluated at the LSOA level using the 'before' and 'after' distances calculated from the network analysis. The associated census, urban/ rural and deprivation attributes were linked to the LSOA data.

The results of evaluating Criterion 1 (' $99 \%$ of the UK population to be within 3 miles and $90 \%$ of the population to be within 1 mile of a post office') are shown in Table 2. Leicester and Leicestershire fails the second clause of the access criteria (90\% within 1 mile) before closures and the situation is worsened by the closures.

The results of evaluating Criterion 2 (' $99 \%$ of the total population in deprived urban areas across the UK to be within 1 mile of their nearest post office') are shown in Table 3. In this analysis 'Urban' areas were those described as 'Urban $>10 \mathrm{~K}$ Less Sparse" in the Urban and Rural classification (there are no sparse or dispersed areas in Leicester and Leicestershire). Deprived LSOAs were those in the 95th 


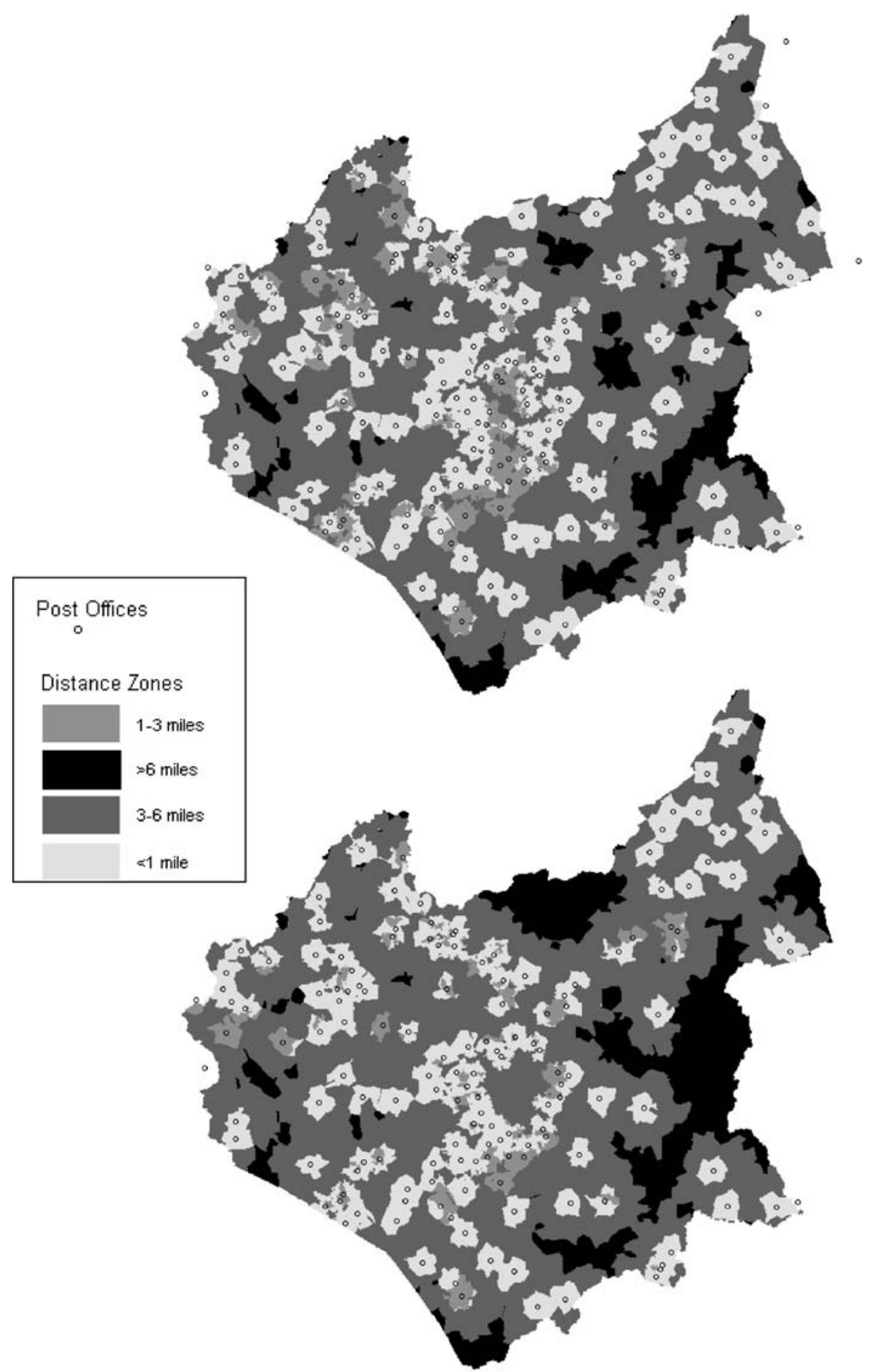

Fig. 2 Road distances to post offices before the proposed closures (top) and after (bottom) in Leicester and Leicestershire 
Table 1 The number of LSOA population weighted centroids in different travel zones before and after post office closures

\begin{tabular}{lcccr}
\hline Before Closures & \multicolumn{2}{l}{ After closures } & & \\
\cline { 2 - 5 } & $<1$ mile & $1-3$ miles & $3-6$ miles & Total \\
\hline$<\mathbf{1}$ mile & 409 & 74 & 0 & 488 \\
$\mathbf{1 - 3}$ miles & 0 & 99 & 0 & 99 \\
$\mathbf{3}-\mathbf{6}$ miles & 0 & 0 & 1 & 1 \\
Total & 409 & 173 & 5 & 583 \\
\hline
\end{tabular}

percentile of the distribution of most deprived LSOAs. The situation was poor before the proposed closures and is worse after, indicating that the impact of post office closures in Leicester and Leicestershire acutely affects those in deprived urban areas.

The results of evaluating Criterion 3 (' $95 \%$ of the total urban population across the UK to be within 1 mile of their nearest post office') are shown in Table 4. This analysis used the same definition of Urban as in Criterion 2 above. The results show that before the proposed closures $14.8 \%$ of the urban population are not within 1 mile of their nearest post office and after the closures this figure rises to $30.0 \%$.

The results of evaluating Criterion 4 (' $95 \%$ of the total rural population across the UK to be within 3 miles of their nearest post office') are shown in Table 5. Rural areas in this analysis were those areas described as 'Village, Hamlet \& Isolated Dwellings' in the Urban and Rural classification. The analysis shows that before the proposed closures $3.2 \%$ of the rural population are not within 3 miles of a post office and after this figure rises to $10.1 \%$.

The proportions of the population in each post code district within 6 miles of a post office was $100 \%$ before and after proposed closures (Criterion 5 'For each individual postcode district, $95 \%$ of the population of the postcode district to be within 6 miles of their nearest post office'). The proposed closures do not alter the distribution of access under this criterion.

In summary, an initial analysis of access to post offices before and after the proposed closures showed that 74 LSOAs moving from the 'less than 1 mile' zone to the '1-3 mile' zone. Evaluation of the Network Change 'access criteria' proposed by the Post Office Ltd shows that all but one of them fails in Leicester and Leicestershire. After closures less than $99 \%$ of the total population are within 3 miles of a post office; many fewer than $99 \%$ of the population in deprived urban areas and $95 \%$ of the total urban population are within 1 mile of their nearest post office and less than $95 \%$ of the rural population are within 3 miles of a post office.

Table 2 Evaluation of the post office access criterion 1 ' $99 \%$ of the UK population to be within 3 miles and $90 \%$ of the population to be within 1 mile of a post office'

\begin{tabular}{llllll}
\hline & $<1$ mile & & $<3$ miles & \\
\cline { 2 - 3 } \cline { 5 - 6 } & FALSE & TRUE & & FALSE & TRUE \\
\hline Before closures & $148420(16.7 \%)$ & $741087(83.3 \%)$ & & $2426(0.3 \%)$ & $887081(99.7 \%)$ \\
After closures & $263881(29.7 \%)$ & $625626(70.3 \%)$ & & $7548(0.8 \%)$ & $881959(99.2 \%)$ \\
\hline
\end{tabular}


Table 3 The proportions of the urban deprived population in Leicester and Leicestershire who are within 1 mile of their nearest post office

\begin{tabular}{lll}
\hline & FALSE & TRUE \\
\hline Before closures & $11860(34.7 \%)$ & $22321(65.3 \%)$ \\
After closures & $16249(47.5 \%)$ & $17932(52.5 \%)$ \\
\hline
\end{tabular}

Only at the postcode district level are the criteria met. These results are summarised in Table 6.

\section{Optimisation of Closures}

As stated above, a GGA approach to suggesting alternative closure plans was investigated. In each case, as well as optimising the objective functions stated above, a constraint was imposed that no LSOA should be more than 6 miles from its nearest post office. Recall, the three possible objective functions considered here were:

1. Mean distance to nearest post office, weighted by total population;

2. Mean distance to nearest post office, weighted by numbers of population with limiting long-term illness (LLTI);

3. Mean distance to nearest post office, weighted by numbers of high-level full time carers (here high level full-time caring is defined as 50 or more hours per week).

It may be verified that in each case above, these objectives are equivalent to the total person-distances to nearest post offices, for persons specified as the subset of the population used to weight the mean. In each case, the closure plan involved finding 48 out of the listed 181 post offices to minimise the respective objective function. The effect of each closure plan is shown in Figs. 3, 4, 5 and 6. In each case, a choropleth map shows the spatial distributions of extra distance to the nearest post office as a result of carrying out the closures chosen to optimise the respective objective function. Figure 3 shows the impacts of the proposed closures. Figures 4, 5 and 6 show alternative spatial distributions of the additional distances for set of closures optimised to minimise the impacts for different groups: Fig. 4 for the whole population, Fig. 5 for the population described as living with limiting long term illness, Fig. 6 for the population described as unpaid carers with care duties exceeding $50 \mathrm{~h}$ per week (high-level full time carers). The application of optimisation routines shows that alternative patterns of closures to minimise the impact in terms of additional distances to post offices for targeted groups are possible.

Table 4 The impact of post office closures on the numbers of the urban population who live within 1 mile of a post office before and after closures

\begin{tabular}{lll}
\hline & FALSE & TRUE \\
\hline Before closures & $103012(14.8 \%)$ & $593026(85.2 \%)$ \\
After closures & $208523(30.0 \%)$ & $487515(70.0 \%)$ \\
\hline
\end{tabular}


Table 5 The numbers of the rural population in Leicester and Leicestershire who are within 3 miles of a post office before and after closures

\begin{tabular}{lll}
\hline & FALSE & TRUE \\
\hline Before closures & $2426(3.2 \%)$ & $72429(96.8 \%)$ \\
After closures & $7548(10.1 \%)$ & $67307(89.9 \%)$ \\
\hline
\end{tabular}

In the actual closure plan, a large number of post offices near to Leicester city centre have been closed, and several urban LSOAs have experienced increased distance to their nearest post office, some over one and a quarter miles. In comparison, the three alternative plans show very little increase in distance in urban areas, and nowhere experiences an increase of greater than 1 mile even in rural areas. Considering the numbers of LSOAs in the different access bands used in Table 1, the effects generally seem better than with the actual closures. This is shown in Table 7. Here, the number of LSOAs still in the 'less than 1 mile' zone is - in each case - a relatively small reduction on the original amount, in comparison to Table 1.

It would seem that, at least in relative terms, the greatest loss of accessibility has fallen on urban dwellers. In particular if access is optimised for those living under difficult conditions - for example those in poor health, or unpaid carers for others, we see a quite different closure pattern than that implemented in reality, with far fewer urban closures. This results from the fact that the greater proportion of such people live in urban areas.

It is also worth noting that even considering the population as a whole, any of the alternative closure plans here result in fewer people experiencing large increases in distance to the nearest post office. This analysis does not argue that the closures were necessary, but does demonstrate that even if they were inevitable, alternative closure plans could have reduced the loss of accessibility when considered for the population of Leicester and Leicestershire as a whole.

\section{Discussion and Conclusions}

The results of this work demonstrate two main things. First, that only one of the Network Change accessibility criteria was fully met by planned post offices closures in the Leicester and Leicestershire area, despite the programme aims to protect consumers in rural, remote and deprived urban areas. Second, that a modelling

Table 6 A summary of the access criteria targets and the extent to which proposed closures meet them

\begin{tabular}{lllccc}
\hline Criterion & Population & Distance & Target & Before closures & After closures \\
\hline $\mathbf{1 a}$ & All & 3 miles & $99 \%$ & $99.7 \%$ & $99.2 \%$ \\
$\mathbf{1 b}$ & All & 1 mile & $90 \%$ & $83.3 \%$ & $70.3 \%$ \\
$\mathbf{2}$ & Deprived urban & 1 mile & $99 \%$ & $65.3 \%$ & $52.5 \%$ \\
$\mathbf{3}$ & All urban & 1 mile & $95 \%$ & $85.2 \%$ & $70.0 \%$ \\
$\mathbf{4}$ & All rural & 3 miles & $95 \%$ & $96.8 \%$ & $89.9 \%$ \\
$\mathbf{5}$ & All in postcode district & 6 miles & $95 \%$ & $100 \%$ & $100 \%$ \\
\hline
\end{tabular}




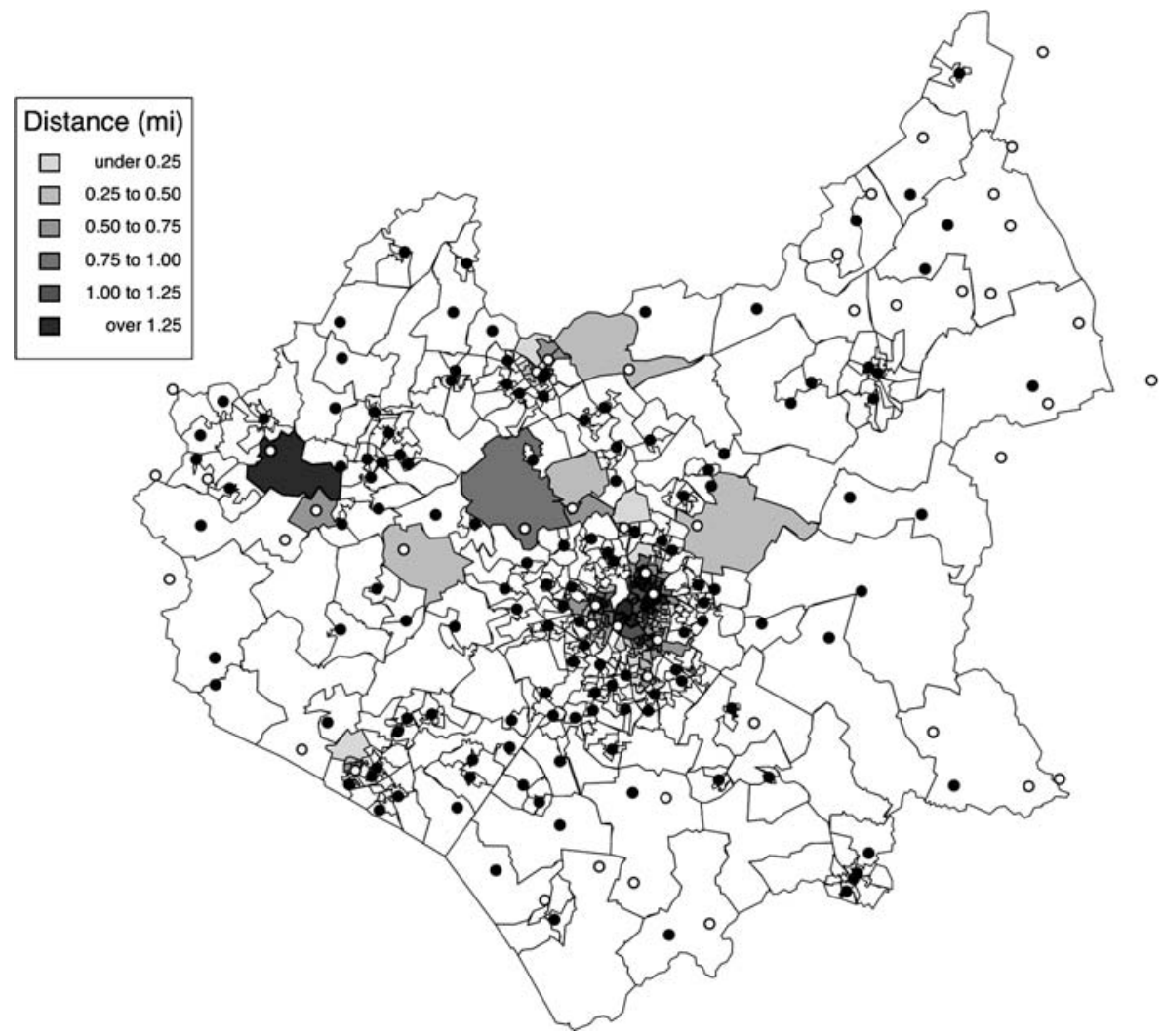

Fig. 3 Closures as recommended in the actual plan showing increased distance to nearest post office. Unaffected LSOAs are unshaded. Dots represent post offices, and those selected for closure are highlighted in white

approach can be used to optimise a network of retail or business outlets, such as post offices. This can be done to maximise accessibility for specific demographic groups, depending on the target customer base.

In this case an optimisation modelling approach reduced the impacts of post office closures for the whole population and for targeted demographic groups (in this case those with limiting long-term illness and full time carers). The results of the targeted optimisation modelling indicate reduced urban post office closures. This is because a greater proportion of such people live in urban areas but even when the whole population are considered we note that the alternative closure plans result in fewer people experiencing large increases in distance to the nearest post office. Whilst in each case, the optimisation resulted in fewer urban closures which might be seen to pose a threat to rural sustainability (i.e. rural closures), Table 6 suggests that overall there are more 'winners' regardless of which of the three optimisations are used than the planned closures. The implication of the results is that alternative closure plans could have reduced the loss of accessibility when considered for the population of Leicestershire as a whole. 


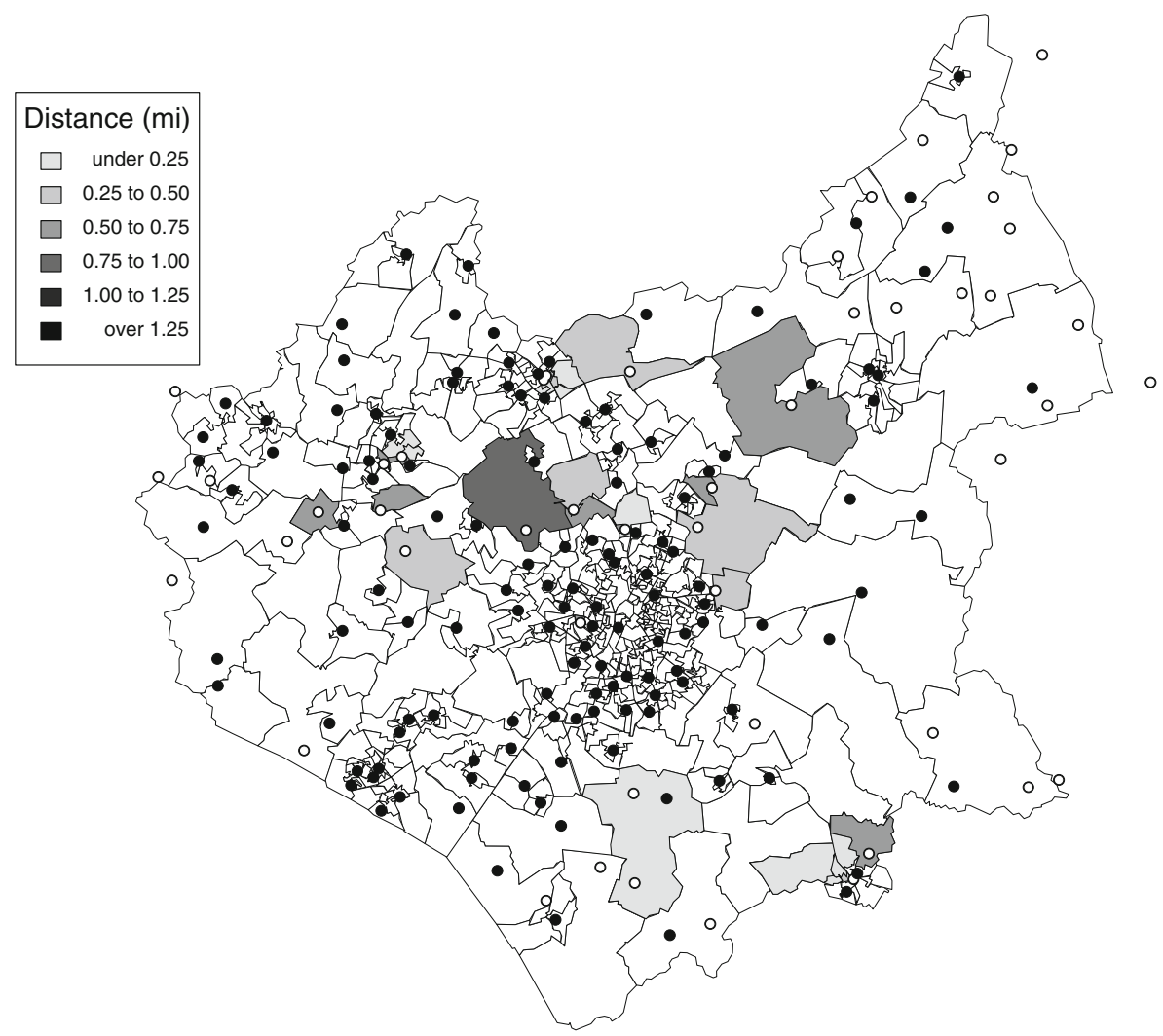

Fig. 4 Closures minimising population weighted mean distance to post office showing increased distance. Unaffected LSOAs are unshaded. Dots represent post offices, and those selected for closure are highlighted in white

This method demonstrates that alternative closure plans can result in fewer people in targeted socio-economic groups (e.g. those associated with rural sustainability) experiencing large increases in distance to the nearest post office and can reduce the impacts of closures for those groups. The application of a GIS-based network analysis linked to census data is a method that could be used to evaluate post office accessibility at national and sub-national levels. The resultant data would be suitable for input into optimisation analysis, modelling alternative post office closures and to provide evidence for informed decision making in spatial planning. The model parameters can be set to minimise the impact of post office closures for any socioeconomic or demographic group by optimising accessibility for different target groups within the population.

In conclusion, a number of post offices are to close. Concern has been expressed over the process by which the decisions to close individual post offices have been made. The method presented in this paper evaluated proposed post office closures at a local (county) level against national targets. Whilst it could be argued that in the context of national objectives local analyses are inappropriate, local authorities have to develop strategies and commit resources that address inequalities, access to 


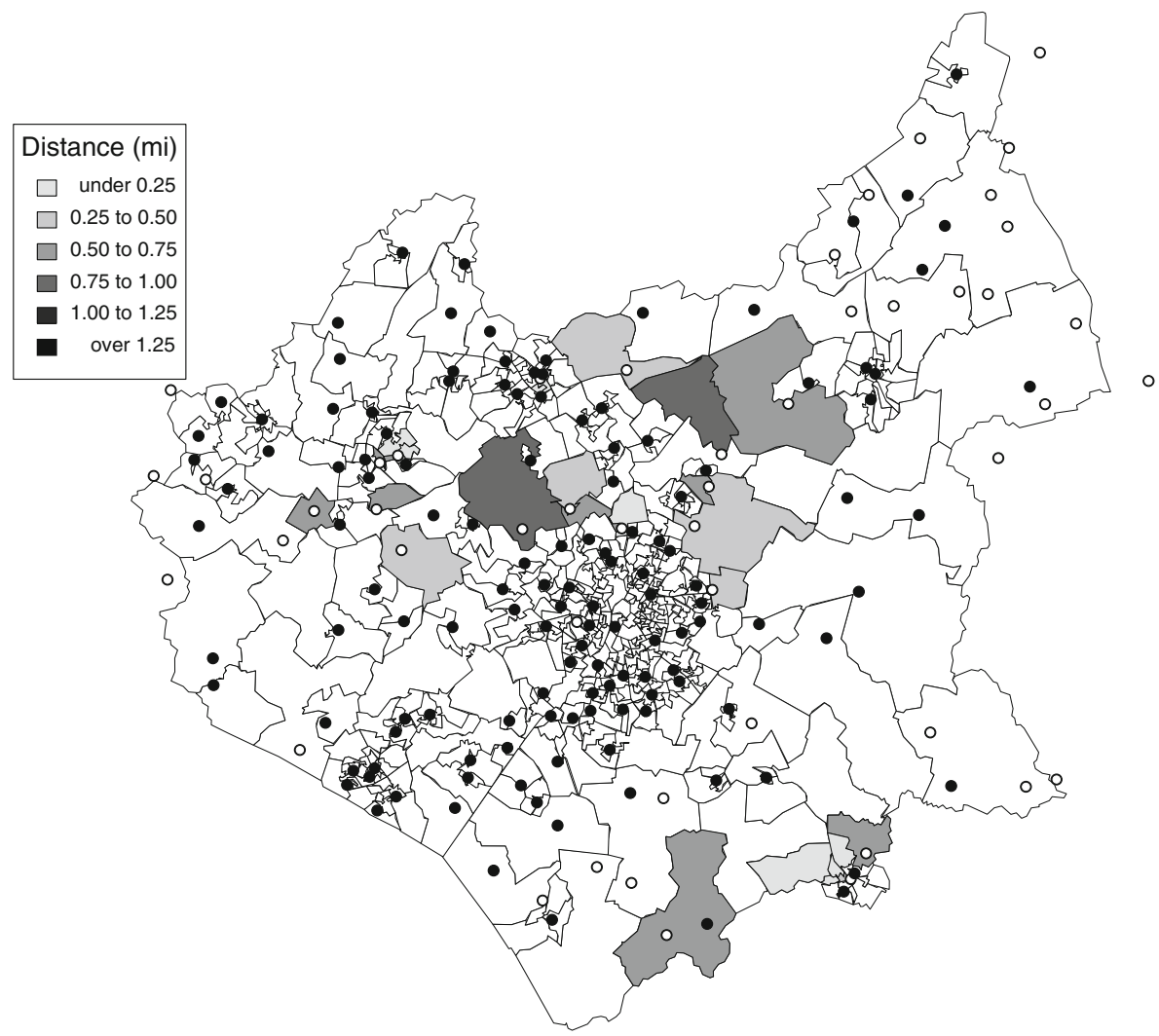

Fig. 5 Closures minimising population-with-LLTI weighted mean distance to post office showing increased distance. Unaffected LSOAs are unshaded. Dots represent post offices, and those selected for closure are highlighted in white

facilities and other dimensions related to community sustainability: they need this kind of analysis. The national targets will results locally 'winners and 'losers' and the method presented in this paper provides a tool for local authorities to evaluate the impacts of closures and to identify alternative closures better suited to local priorities. The value of the method presented in this analysis is that it allows decisions to be made that optimise the selection of retail outlets (in this case post offices to be closed). The LSOA data can be considered as 'demand' and the post office as 'supply'. By optimising selection based on 'demand' access this method can be applied to select individuals within any given spatially dispersed 'supply' network using a set relevant criteria (e.g. based on market characterisation).

The results of this work showed that at a local level current planned post offices closures by Post Office Ltd fail to meet the accessibility criteria that they describe under the Network Change programme. At least at the local level, the process of selecting post offices to close does not seem to have been fully effective in meeting the needs of those in rural and deprived urban communities, even when evaluated against Post Office Ltd's own access criteria. The approach presented in this paper 


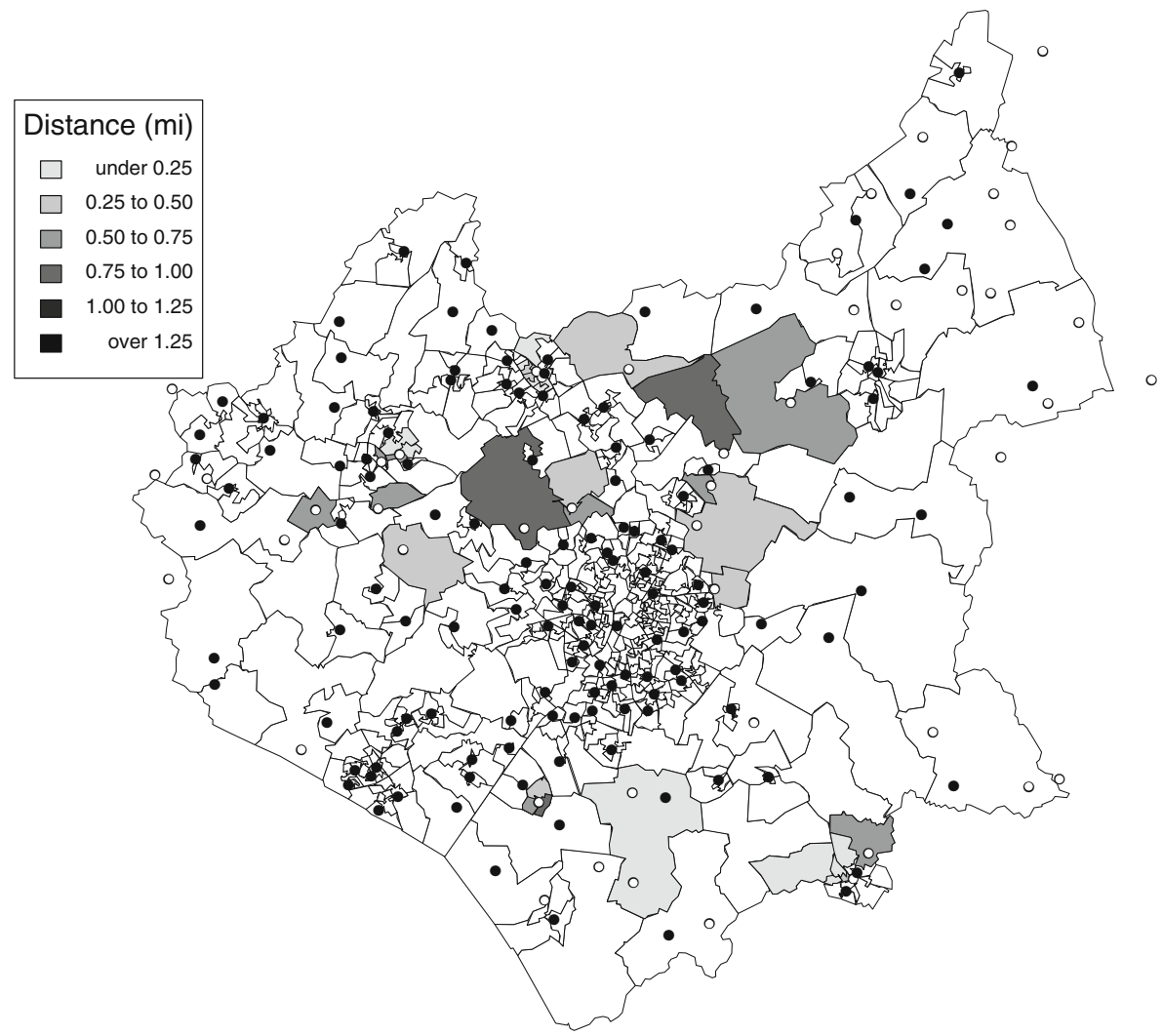

Fig. 6 Closures minimising population-as-high-level-carers weighted mean distance to post office showing increased distance. Unaffected LSOAs are unshaded. Dots represent post offices, and those selected for closure are highlighted in white

Table 7 LSOA travel zones based on optimisation algorithms by urban/rural classes

\begin{tabular}{llcrrr}
\hline Optimisation & Classification & $<$ 1 Mile & 1-3 Miles & 3-6 Miles & Total \\
\hline Population & Urban & 387 & 73 & 0 & 460 \\
& Town/Fringe & 72 & 3 & 0 & 75 \\
& Rural & 18 & 29 & 1 & 48 \\
& All & $\mathbf{4 7 7}$ & $\mathbf{1 0 5}$ & $\mathbf{1}$ & $\mathbf{5 8 3}$ \\
LLTI & Urban & 388 & 72 & 0 & 460 \\
& Town/Fringe & 72 & 3 & 0 & 75 \\
& Rural & 18 & 29 & 1 & 48 \\
& All & $\mathbf{4 7 8}$ & $\mathbf{1 0 4}$ & $\mathbf{1}$ & $\mathbf{5 8 3}$ \\
Carer & Urban & 388 & 72 & 0 & 460 \\
& Town/Fringe & 69 & 6 & 0 & 75 \\
& Rural & 18 & $\mathbf{1 0 7}$ & 1 & 48 \\
& All & $\mathbf{4 7 5}$ & $\mathbf{1}$ & $\mathbf{5 8 3}$ \\
\hline
\end{tabular}


provides a tool that addresses the concerns of Postcomm, the post office regulator, and House of Commons Business and Enterprise Committee over the calculation and validation of access criteria. This method supports transparency in spatial planning and decision-making by providing evidence and to quantify the implications of closure proposals. Future work will consider different combinations of demographic factors to optimise decision making and will explore the development of software that runs optimisation in conjunction with network analyses.

\section{References}

Age Concern (2006). Rural post offices are a lifeline and centre of the community, Age Concern, London. http://ageconcern.org.uk/AgeConcern/Documents/Rural_post_offices_report.pdf [available 26th July 2008].

Bibby, P. \& Shepherd, J. (2004). Developing a New Classification of Urban and Rural Areas for Policy Purposes - the Methodology https://statistics.defra.gov.uk/esg/rural_resd/rural_defn/Rural_Urban_ Methodology_Report.pdf [available 26th July 2008].

Boston Borough Council (2006). A Sustainability Study of the Rural Settlements Consultation of Stage One-The Methodology. http://www.boston.gov.uk/index.php?option $=$ com_docman\&task $=$ doc view\&gid $=915$ [available 26th July 2008].

Comber, A. J., Brunsdon, C., \& Green, E. (2008). Using a GIS-based network analysis to determine urban greenspace accessibility for different ethnic and religious groups. Landscape and Urban Planning, 86, $103-114$.

Commission for Rural Communities (2007). The State of the Countryside 2007. Cheltenham Spa: Commission for Rural Communities.

Devlin, G. J., McDonnell, K., \& Ward, S. (2008). Timber haulage routing in Ireland: an analysis using GIS and GPS. Journal of Transport Geography, 16(1), 63-72.

European Community (1997). Council Directive 97/67/EC of 15 December 1997 on common rules for the development of the internal market of Community postal services and the improvement of quality of service. Official Journal of the European Communities, L15/14-L15/25.

Falkenauer, E. (1999). Genetic algorithms and grouping problems (1999). London: John Wiley and Sons Ltd.

Higgs, G., \& White, S. D. (1997). Changes in service provision in rural areas. Part 1: The use of GIS in analysing accessibility to services in rural deprivation research. Journal of Rural Studies, 13(4), 441450.

House of Commons Business and Enterprise Committee (2008). After the Network Change Programme: the future of the post office network. 6th Report of Session 2007-8. http://www.parliament.thestationery-office.co.uk/pa/cm200708/cmselect/cmberr/577/577.pdf [available 26th July 2008].

McLafferty, S. L. (2003). GIS and health care. Annual Review of Public Health, 24, $25-42$.

Onega, T., Duell, E. J., Shi, X., Wang, D. M., Demidenko, E., \& Goodman, D. (2008). Geographic access to cancer care in the U.S. Cancer, 112(4), 909-918.

O'Sullivan, D., Morrison, A., \& Shearer, J. (2000). Using desktop GIS for the investigation of accessibility by public transport: an isochrone approach. International Journal of Geographical Information Science, 14(1), 85-104.

Post Office Ltd (2008). Network Change Programme. http://www.postoffice.co.uk/portal/po/jump2?catld = $63400714 \&$ mediald $=57600693$ [available 26th July 2008].

Postcomm (2006). Government must decide quickly the future of a Post Office Network that is 'at the crossroads http://www.psc.gov.uk/news-and-events/news-releases/2006/government-must-decidequickly-the-future-of-a-post-office-network-that-is-at-the-crossroads.html [available 7th November 2008].

Postcomm (2007). Postcomm's response to The Post Office Network Consultation. http://www.psc.gov.uk/ postcomm/live/post-offices/research/response_to_PO_condoc.pdf \{available 26th July 2008].

Postwatch (2008). Post office closures. http://www.postwatch.co.uk/index.php?option $=$ com_content\& task $=$ view\&id $=35 \&$ Itemid $=30$ [available 26th July 2008]. 
R Development Core Team (2008). R: A Language and Environment for Statistical Computing, The R Foundation for Statistical Computing, Vienna, Austria, http://www.R-project.org.

Schuurman, N., Fiedler, R. S., Grzybowski, S. C. W., \& Grund, D. (2006). Defining rational hospital catchments for non-urban areas based on travel-time. International Journal of Health Geographies, 5 , 43.

White, S. D., Guy, C. M., \& Higgs, G. (1997). Changes in service provision in rural areas. Part 2: Changes in post office provision in mid Wales: A GIS-based evaluation. Journal of Rural Studies, 13(4), 451465.

Wyatt, P. J. (1997). The development of a GIS-based property information system for real estate valuation. International Journal of Geographical Information Science, 11(5), 435-450. 